This article was downloaded by: [University of Udine]

On: 30 July 2010

Access details: Access Details: [subscription number 921208708]

Publisher Routledge

Informa Ltd Registered in England and Wales Registered Number: 1072954 Registered office: Mortimer House, 3741 Mortimer Street, London W1T 3JH, UK

\title{
Cataloging Classification
}

\section{Cataloging \& Classification Quarterly}

Publication details, including instructions for authors and subscription information: http://www.informaworld.com/smpp/title $\sim$ content=t792303976

\section{From Bibliographic Models to Cataloging Rules: Remarks on FRBR, ICP,} ISBD, and RDA and the Relationships Between Them

Carlo Bianchini ${ }^{\mathrm{a}}$; Mauro Guerrini ${ }^{\mathrm{b}}$

${ }^{a}$ Natural History Museum, Udine University, Udine, Italy ${ }^{b}$ Florence University, Florence, Italy

R Routlodge

To cite this Article Bianchini, Carlo and Guerrini, Mauro(2009) 'From Bibliographic Models to Cataloging Rules: Remarks on FRBR, ICP, ISBD, and RDA and the Relationships Between Them', Cataloging \& Classification Quarterly, 47: 2, 105 124

To link to this Article: DOI: $10.1080 / 01639370802561674$

URL: http://dx.doi.org/10.1080/01639370802561674

\section{PLEASE SCROLL DOWN FOR ARTICLE}

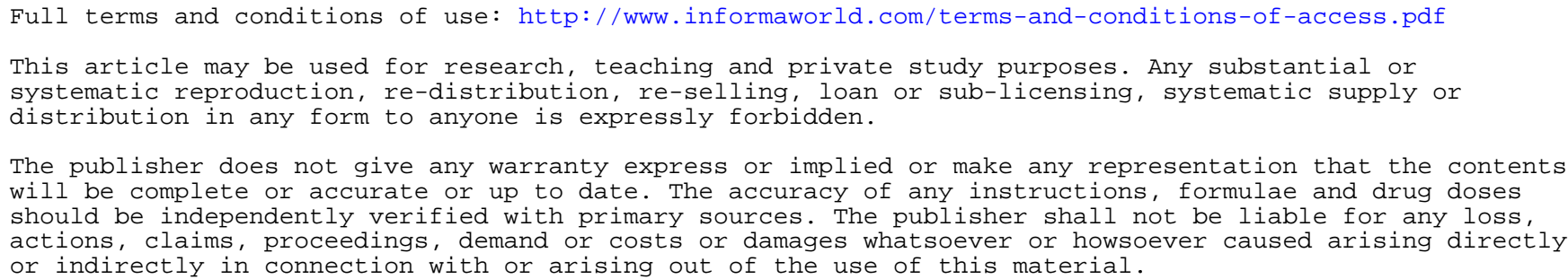




\title{
From Bibliographic Models to Cataloging Rules: Remarks on FRBR, ICP, ISBD, and RDA and the Relationships Between Them
}

\author{
CARLO BIANCHINI \\ Natural History Museum, Udine University, Udine, Italy \\ MAURO GUERRINI \\ Florence University, Florence, Italy
}

\begin{abstract}
This article discusses the changes that are occurring in the world of cataloging. It argues that these changes need to be coordinated. It also discusses the feature of current OPACs, FRBR, the Paris Principles and its proposed replacement (ICP), AACR2 and its proposed replacement (RDA), ISBD, and the relationships between and among these standards. It argues that the syntax of ISBD is an essential component of RDA and all future international and national cataloging codes.
\end{abstract}

KEYWORDS Cataloging, ICP, RDA, FRBR, ISBD, principle of local variation

A reader may know the work he requires; but he cannot be expected to know all the peculiarities of different editions, and this information he has right to expect from the catalogues. ${ }^{1}$

-Antonio Panizzi

Received 17 June 2008; revised 1 October 2008; accepted 12 October 2008.

This article was written in two stages. The first stage is the result of a discussion promoted by Elena Escolano Rodriguez, Chair of the ISBD Review Group of the IFLA Cataloguing Section. Pino Buizza, Elena Escolano Rodriguez, Michael Gorman, Lynne Howarth, and Dorothy McGarry contributed to the discussion and supported our work. The second stage is the result of the requests of explanation by Sandy Roe, Editor of Cataloging E Classification Quarterly, and two anonymous reviewers. These requests pressed us for more considerations and additions to the article, and, above all, they allowed us to begin a larger and very enriching discussion with Michael Gorman, Dorothy McGarry, and Barbara B. Tillett and to reach otherwise unattainable results.

Address correspondence to Mauro Guerrini, Florence University, Dipartimento Medioevo e Rinascimento, Piazza Brunelleschi 4-50121 Firenze-IT. E-mail: mauro.guerrini@unifi.it 


\section{INTRODUCTION}

The international cataloging community is dealing with enormous changes in cataloging principles, standards, and rules. Managing these changes is not easy, as they are both highly complex and strongly inter-related. Change implies a major movement from one state to another. In the case of cataloging, this means that we have to deal with our cataloging theory and practice being completely restructured on the basis of the Functional Requirements for Bibliographic Records (FRBR). ${ }^{2}$ We are asked to think in terms of $F R B R$, but we are using pre-FRBR designed catalogs and there is a growing sense that they are not completely adequate for our needs and wishes, nor for those of our users. Further, we also have to take into consideration the fact that cataloging no longer applies just to libraries, but also to a wider range of institutions, with models, needs, and wishes that are similar to ours in some respects and different in others.

The process of revising our cataloging principles, and switching from the functions of the catalog to the needs of more general users, is under way. The IFLA Meeting of Experts on an International Cataloging Code (IME ICC) is very close to formulating a definitive Statement of International Cataloging Principles (ICP). ${ }^{3}$ Work has also proceeded on improving the International Standard Bibliographic Description (ISBD); the preliminary consolidated edition has been published. ${ }^{4}$ Also, many countries are changing their national cataloging codes, both to update them to the new context and to create new structures for future catalogs.

For many reasons, this is a very difficult process. Not only is each change complex, but many changes are going on simultaneously and none of them can rely on any of the others, because everything is changing at the same time. Complexity is greater than it would be for each single process. For this reason, each change has to be considered with an increasing level of care.

Unfortunately, this is not enough. This is the question we should consider: Who is looking after the whole process of the renewal of cataloging? To put it another way: Who is guiding the relationships among FRBR, the new Cataloging Principles (ICP), the ISBD consolidated edition, and national and multinational and international cataloging codes (e.g., RDA-Resource Description and Access)?

The bibliographic universe can be managed only through unceasing interaction between theory and practice. We now have the strong influence of a theoretical model (FRBR) on all our practices, but there is no productive interaction between that theory and cataloging practice. We believe there must be a fundamental break with past practice, in order to make room for completely new models and tools. However, the shift from past to future must not prevent us from thinking of the present, too. In particular, we urgently need to reach agreement on a definition of the correct relationships 
between FRBR, ISBD, and national, multinational, and international codes-chiefly RDA.

Recently, two critical points in the relationship between ISBD and RDA have arisen. The first, a problem partly solved recently, centered on important differences in mandatory elements in ISBD and RDA. In a recent decision, ${ }^{5}$ advocated strongly by the ISBD Review Group and the FRBR Review Group, the JSC agreed that a statement of responsibility following a title proper and transcription of an additional edition statement are important for identification and selection and therefore would be added to the RDA core element set. With this decision, the body responsible for RDA-the Joint Steering Committee for Development of RDA (JSC)_gave a clear sign of its prompt attention to requests coming from the international cataloging community. ${ }^{6}$ The second point is a more general problem. It refers to the role given to ISBD within RDA, and to description within FRBR. This issue will be discussed here in the frame of a general need for coordination of the numerous and different changes that are occurring and are yet to occur.

\section{FROM BOOK CATALOGS TO OPACS: ARE WE LOSING SIGHT OF SOMETHING?}

In book and other pre-card catalogs, bibliographic descriptions took the form of entries displayed hierarchically. As Svenonius notes "under each (main) author's name were listed alphabetically by title the works written by him. The first edition of a work held by the library was described in full. If the library held a second edition, its entry was listed under that for the first as: '_ Another edition.' If needed, information that served to distinguish it from the first would be given. If the library held more than a copy of an edition, it was described as: "—_ Another copy."”7 This solution was a good way to save time and money, but its primary function was to collocate in a hierarchical structure entities such as works, publications, editions, and copies. Further, "in book catalogs, relationships of a non-hierarchical kind (that is, other than membership and inclusion) were indicated by cross-references." 8

Book catalogs gave way to card catalogs, but these brought with them some disadvantages, and caused a change in the way bibliographic information was represented: "specifically, dashed entries no longer were appropriate; instead each document had to be described in full [our emphasis], using (normally) one card per document. As a result some of the economy and structure [our emphasis] afforded by hierarchical representation was lost. [...] Elaborate filing rules were created for this purpose, so that the order of records in a card catalog mimicked the hierarchical ordering of entries in a book catalog." Dashes were relevant not as display format, but as expression of a hidden strong bibliographic structure. 
The change from card to online catalogs involved a "loss of bibliographic structure. The tiered structure, so neatly displayed in book catalogs and more or less preserved by strict filing rules in card catalogs, has been lost almost altogether [... and] the syndetic structure, the structure used to guide users [...] has not been implemented." 10 In fact, in card catalogs, the See also references provided a syndetic structure.

Lastly, the use of new forms of catalog created a conflict between the finding (specific search) and collocating (search for like materials) functions of the catalog "so that records designed for one function do not suffice for the other" 11 and the question of the purpose of bibliographic records has become more and more urgent. Technological advances have caused catalogs to be seen as bibliographic tools designed to meet user-oriented objectives. The inventory and finding functions are still important, but "it does not follow, however, that inventorying still requires a one-to-one relationship between items and their surrogates." 12

Two inferences can be drawn from the transition from book to online catalogs: (a) some economy in representation of bibliographic information was lost and (b) the syndetic structure of catalogs has not been fully implemented in online catalogs.

Lubetzky observed "using the capacity of the computer to retrieve a certain book by means of a few uncommon elements from the title page obviates the whole problem incidental to the use of the author's name. But note that the online catalog serves only the first objective of the catalog-to help the reader find the particular book he or she wants." 13

Ever since the publication of the first international cataloging code of 1908, provision has been made for the use of both main entry and added entries. But the "use of an added entry-would vitiate the purpose of the main entry. For if a reader looked in the catalog under the title of the book he or she wants and finds it there, that would end the search."14

Catalogs should take full advantage of new technologies, to create structures able to satisfy both the inventory and collocating functions of the catalog. In his bibliographic masterpiece, Konrad Gesner suggested a way to meet both functions: he suggested using his Bibliotheca Universalis as a list of books to which any library could add book numbers to obtain its own catalog. This idea would go to another level with Panizzi's Rules ${ }^{15}$ because each user of the catalog constructed in accordance with those rules finds each item in its proper and complete bibliographic context.

From the point of view of the user, how can the catalogs of today be browsed? Although modern catalogs offer many access points, they still lack a way to express their syndetic structure fully, to define their arrangement, and to represent in one structure the whole bibliographic universe (or of that part of the bibliographic universe that is represented in the holdings of the library and matches a user's search). 


\section{FUNCTIONAL REQUIREMENTS FOR BIBLIOGRAPHIC RECORDS (FRBR)}

The currently accepted theoretical model for cataloging is FRBR. The ideas behind this model are developed at a very high level of logic. It is founded on well-defined ideas about the objects that constitute our bibliographic universe (works, documents, authors, publishers, etc.) and it places those objects into groups with special attributes and relationships. A model is, essentially, a complex of ideas; to speak in FRBR terms, we could say that the FRBR model is "a work" in the minds of the cataloging community. The conceptual model of our bibliographic universe based on FRBR study is evolving too, as the recently published object-oriented version of FRBR proves. ${ }^{16}$ In fact, as an abstract model, the idea of the bibliographic universe can take many shapes, it can be carried out in many different "expressions." To represent the bibliographic universe, the Paris Principles provided for the functions of the library catalog; now FRBR is centered on the perceived informational needs of users or "user tasks": ${ }^{17}$ that's why there is now a need for new expressions of the same principles.

FRBR has two objectives: "to provide a clearly defined, structured framework for relating the data that are recorded in bibliographic records to the needs of the users of those records," and "to recommend a basic level of functionality for records created by national bibliographic agencies." ${ }^{18}$ We would argue that FRBR is an innovative and helpful snapshot obtained-not solely - from the examination of bibliographic records based on ISBD. ${ }^{19}$ In other words, all the objects (entities, relationships, and attributes) delineated by FRBR are found within the ISBDs.

Because the FRBR model "does not cover the extended range of attributes and relationships that are normally reflected in authority records," 20 the proposed Functional Requirements for Authority Data (FRAD) and Functional Requirements for Subject Authority Records (FRSAR) need to be developed.

Another very important feature of FRBR must be remembered here, because it is directly related to our topic: the approach adopted within FRBR "endeavours to define in a systematic way what it is that the user expects to find information about in a bibliographic record and how that information is used." 21 The focus is both on the function of the data (how information is used) and on entities (what information is about). FRBR is a conceptual model of the entities and relationships, so it never deals with data description and presentation and does not deal with how data can or must be communicated. The FRBR report based its analysis on ISBD (the international standard for bibliographic description) and establishes the important elements for a national bibliographic record, but is not interested in description and does not prescribe cataloging rules. Nowhere in FRBR can one find information about central matters such as sources of bibliographic information, 
language or script of the description, abridgements and abbreviations, capitalization, misprints, and so on. Even less is it possible to find in FRBR information about the analysis of the item in hand, or about how the catalog communicates with the users, or about the order of the data within a single bibliographic record or in the catalog as a whole. It is, after all, a conceptual model, not a set of cataloging rules.

In this perspective, the expression "FRBR catalog" makes no sense (or so ambiguous a sense to not be useful), because the use of the FRBR model in catalog requires at least the adoption of a bibliographic language and a code of cataloging rules. For example, merely possessing a ball, does not tell us how to play football nor volleyball, absent the dimensions of the pitch, the number of players, and a more or less complex set of rules. In this case, the expression "FRBR catalog" is the logical equivalent of "to play with a ball" and about as much use in practical application.

\section{NEW CATALOGING PRINCIPLES (ICP)}

Since 1961, the only internationally generally agreed cataloging principles have been the Paris Principles, which have been the basis of many national cataloging codes. ${ }^{22}$ The task today is to consider those principles from the point of view of the users rather than from the point of view of the catalog.

The proposed revision of those principles (the ICP) suggests not only a change of view from the functions of the catalog to the users' needs, but also enlarges its scope: "These new principles replace and broaden the Paris Principles from just textual works to all types of materials and from just the choice and form of entry to all aspects of the bibliographic and authority records used in library catalogues." 23

The most important change lies in the extension of the ICP to "all aspects of the bibliographic and authority records." 24 The Paris Principles declared in a footnote that "in this Statement, the word 'book' should be taken to include other library materials having similar characteristics" 25 and, above all, AACR2 was medium neutral and covered all types of resources. Nevertheless, even if in the cataloging community there is a tendency to consider the Paris Principles obsolete, it is yet to be proved that this change of perspective is sufficient to abandon the Paris Principles or that the ICP requires catalogs to perform logical tasks that are fundamentally different from those defined by Cutter's "Objects of the catalog." 26 Rather, we should recognize that there is a straight line from the Paris Principles to the ICP, and that they differ mostly in the updating of terminology to express a new and wider model of the same bibliographic universe.

In the recently published draft of the ICP, a whole section is devoted to general principles "that direct the construction of cataloguing codes." 27 They 
all have the utmost importance, but it is necessary to remember in particular two objectives, as they directly relate to description:

0.3. Representation. Entities in descriptions and controlled forms of names for access should be based on the way an entity describes itself.

0.4. Accuracy. The entity described should be faithfully portrayed. ${ }^{28}$

The wording of the principle of representation originally formulated by Svenonius referred to "descriptions" 29 and not to "entities in descriptions and controlled forms of names for access" (emphasis ours). Actually, it would require descriptions to be constructed to reflect the way bibliographic entities represent themselves. The difference is clearer if we note that it is used "primarily to ensure accuracy of description, though it is used as well to contain costs [and] to prevent idiosyncratic descriptions." 30

Changing the focus of the principle of representation from descriptions to entities in descriptions might seem a minor change-it is not, because the concept of description could equally apply not only to the entities defined in the FRBR study but also to the catalog and to its ability to represent the bibliographic universe. ${ }^{31}$

The principle of accuracy affirms that "truthfully transcribing how a document represents itself is necessary for the identification and communication of bibliographic information." 32 The focus of this principle is the identification and communication of information (neither bow information is used nor what information is about).

The principle of representation has limitations, because if carried too far it would "result in bibliographic descriptions that taken collectively are inconsistent." 33 To facilitate human scanning of lists of descriptions, certain aspects of descriptions need to be made uniform. These include the selection of data elements, the order in which they are displayed, and their punctuation, capitalization, and abbreviation.

Finally, it must be noted that "descriptions cannot consist of derived data alone because the language in which a document represents itself is not necessarily the one a user would use to look for the document."34

\section{INTERNATIONAL STANDARD BIBLIOGRAPHIC DESCRIPTION (ISBD)}

ISBD has been and still is the most successful international cataloging standard ever ${ }^{35}$ and we must carefully consider its future use and developments. In particular, we must consider how relationships among theoretical models, international principles, international standards, and multinational or national rules must or can be guided. 
A layer of complexity was added when IFLA started an ISBD revision process after the FRBR Report was published. FRBR started from the analysis of the ISBD and, in the meanwhile, ISBD evolved from eight texts to the present consolidated edition in "the effort to bring description of all materials to the same state of conformity with FRBR." 36 The new text offers the fundamental basis for creating integrated and resource-oriented OPACs, suggesting to "use the ISBD as the basis for their rules on description of library materials, to describe all aspects of the resource, including its content, its carrier and its mode of issuance." 37

Further, we should also remember the results of Tom Delsey's Mapping ISBD Elements to FRBR Entity Attributes and Relationships, ${ }^{38}$ which showed that many attributes that are present in ISBD but are not yet defined in FRBR, and also that each element in FRBR always has a correspondence to ISBD. Even if the FRBR model presents a completely new point of view of our bibliographic universe, this allows us to have a clearer comprehension but does not really change the bibliographic universe itself: de facto, and for the reasons already discussed, our description practices remain as they are.

This is a key point, and it must be made clear. Since Herman H. Henkle's Report, ${ }^{39}$ cataloging has been based on the idea that bibliographic description and access are clearly distinct. ${ }^{40}$ Description is concerned with bibliographic resources (books, computer resources, music, etc.), whereas access and the syndetic structure are concerned with works found in the bibliographic universe (of which the bibliographic resources are the manifestation), such works having no independent physical existence. A description is a statement of the properties of a thing or its relations to other things serving to identify it. ${ }^{41}$ Any bibliographic research, leaving aside access points, gives as a result one or more descriptions. The Henkle Report clearly states that bibliographic description has its own objectives, namely:

1. to describe the significant features of the book which will serve

(a) to distinguish it from other books and other editions of this book, and

(b) characterize its contents, scope, and bibliographical relations;

2. to present the data in an entry which will (a) fit well with the entries of other books and other editions of this book in the catalogue, and (b) respond best to the interests of the majority of readers. ${ }^{42}$

If you substitute "bibliographic resource(s)" for "book(s)" in these statements, they remain as true as when they were written more than 60 years ago.

There is no doubt that many of the "significant features" of the resource are to be represented by the attributes of the entities and by relationships, as defined by FRBR. However, other fundamental attributes of bibliographic description are to present data in a specific form, consistent with other descriptions, and thus responding best to the interests of the majority of our users. 
Parts of the original purpose of ISBD seem to be less relevant now, when considered in the light of new models coming from FRBR. For example, there are fewer and fewer cases in which ISBD can help us in "in the conversion of bibliographic records to electronic form," as data is increasingly produced directly in electronic form. However, other, more relevant, parts of its functions are still needed now, in particular, the presentation of descriptive data relating to a single resource and to multiple descriptions of resources in a list, (i.e., a more or less complex context).

From the beginning, OPACs were created with the idea that their overriding purpose consists in finding a single piece or a set of well-defined information about a group of resources sharing common characteristics. From this point of view, it is logical to assume that the difference between "main entry" access points and other access points is no longer relevant. If we consider only entities and their attributes and relationships, we could also deduce that traditional bibliographic descriptions are no longer useful. However, if we look at OPACs as they should be, that is, a means of description of, and access to, the bibliographic universe as a whole (to be used also to extract single pieces of information), we are obliged to recognize that, to make them comprehensible - to give them a meaningful sense-we still need both (a) access points - that provide for how the catalog can be arranged, structured, and browsed and (b) internationally agreed-on bibliographic descriptions that enable predictable, consistent displays of data.

It is very important to recognize that the ISBD has many functions and roles in the catalog. ISBD is not only a visual display, nor just a form for presenting the elements. ISBD consists of more than a prescription for punctuation, and it must not be confused with its punctuation. It provides also instructions for data analysis, that is, it gives stipulations to the cataloger to search for and recognize data, to define the functions of each data element within the specific context and to ascertain the proper position for recording the data element within the areas of the description. Even though punctuation is a striking and relevant aspect of ISBD, it has a minor relationship to display issues. In fact, its most important function is to demarcate grammatical links between data elements and to clarify their respective (logical) position by giving them a specific, understandable, meaningful sequence. Only this function actually helps us to understand the real meaning of data elements across linguistic barriers.

Two examples will help to understand this major difference better: if we consider a bibliographic entry written in the 1950s, we can recognize the distinct data elements but, if the punctuation is not normalized, we cannot completely understand the logical functions and relationships of those data elements. This means that ISBD punctuation not only separates data elements, but also defines their logical sequence, allowing the reader to understand their syntactical function and grammatical value. Further, it must be noted that, as far as possible, in ISBD the grammatical structure is preserved 
also within each data area; this is clearly due to the wish to preserve human intelligibility of the bibliographic entry as a text rather than a set of data.

A second example comes from conversion of bibliographic records from old catalogs to new OPACs: in most cases it was impossible simply to copy the old entry into the new ISBD schema, and it was necessary to have the item in hand to complete the cataloging properly. This was due to the necessity for a new analysis. This means that a set of bibliographic data does not always correspond to an ISBD text (i.e., to a bibliographic description).

Within ISBD, the sequence of presentation of the data is meaningful to human beings both for analysis and for the syntactical value of each element; outside of ISBD, any presentation of a set of data-any OPAC labeled display—needs to be explained to be understood by the user.

\section{RESOURCE DESCRIPTION AND ACCESS (RDA)}

AACR2 is to be replaced by RDA, but this change is not without difficulties. The international cataloging community should appreciate the huge efforts the Joint Steering Committee for Development of RDA is making in attempting to create the framework for future catalogs. We should support the RDA effort. Moreover, we should also recognize that before RDA, there was no project to create the basis for a catalog starting from the FRBR study. This shift is even more important because the JSC has abandoned the adjective Anglo-American to declare more clearly the aspiration of RDA to be an international code.

Cataloging describes the bibliographic universe using a very special language. As with all languages, this one follows rules relating to its context, its purposes, and all of its components (vocabulary, semantics, syntax, and pragmatics). ${ }^{43}$

Vocabulary and semantic components are well represented by entities and their attributes and relationships already defined in the FRBR model. On this basis, RDA has developed its new structure, not without many understandable difficulties and unavoidable second thoughts:

"Recording attributes

- "Section 1 - Recording attributes of manifestation and item

- "Section 2 - Recording attributes of work and expression

- "Section 3 - Recording attributes of person, family, and corporate body

- "Section 4 - Recording attributes of concept, object, event, and place"

"Recording relationships

- "Section 5 - Recording primary relationships between work, expression, manifestation, and item 
- "Section 6 - Recording relationships to persons, families, and corporate bodies associated with a resource

- "Section 7 - Recording subject relationships

- "Section 8 - Recording relationships between works, expressions, manifestations and items

- "Section 9 - Recording relationships between persons, families, and corporate bodies

- "Section 10 - Recording relationships between concepts, objects, events, and places." ${ }^{44}$

This is a new and very interesting approach; but, while any attribute and relationship of any entity is recorded, as can be argued from the table of contents, within the text proper there is no section devoted to description of bibliographic resources or to the presentation of the data so accurately recorded.

This is consistent with the pattern of the FRBR study, and explicitly admitted in the drafts of RDA: "One of a number of key elements in RDA is that it establishes a clear line of separation between the recording of data and the presentation of data. The major focus of RDA will be on providing guidelines and instructions on recording data to reflect attributes of, and relationships between, the entities defined in FRBR and FRAD." ${ }^{45}$ RDA focuses mainly on data rather than presentation; this is a clear, declared choice that is correct-if only from an FRBR point of view. FRBR itself acknowledges that it is not a model for a complete catalog, because analysis of authority data and subject authority data are still missing. ${ }^{46}$ It is also incomplete because it lacks both syntax and pragmatics. Where in the FRBR model can stipulations for presentation of bibliographic records be found? Where can stipulations relating to the organization of the whole catalog be found? ${ }^{47}$ An author search in the online catalogs of the Library of Congress, of the British Library, and of the Servizio Bibliotecario Nazionale (http://opac.sbn.it/) shows that results are arranged in the first case by author and title, ${ }^{48}$ in the second one by "Title, then Year," and in the third one in an incomprehensible way. In all the OPACs, results can be resorted. But no one is able to arrange records by works, or expressions, as FRBR, ICP, and above all users would require. Author search is an easy example: What could happen to the arrangement of records obtained by a subject search?

FRBR is neither a cataloging code nor a bibliographic language; and code makers that base their work on the FRBR model must be well aware of this. In fact, in RDA, appendices include some dealing with capitalization, abbreviations, initial articles, record syntaxes for descriptive data, and record syntaxes for access point control data. An appendix of "a book is extra information that is placed after the end of the main text." ${ }^{\prime 2}$ ISBD is much too important a part of cataloging to be relegated to an appendix in RDA. It could be argued that, in an online edition, a reference to an appendix in 
which the order of elements, the prescribed punctuation, and other guidance on the application of ISBD (or any other bibliographic format) in the RDA context is sufficient. We would argue the opposite because: (1) the appendix is, by definition, extra or after the text and this means that RDA itself lacks in prescriptions for presentation of data; (2) the reference in the appendices to ISBD together with reference to MARC 21 (which is a framework standard not a content standard) and Dublin Core (which is, after all, only a limited sub-set of the MARC record), could confuse the reader as to their different meanings and values; 3) the reference to the appendix would be sufficient only if ISBD were just a form of presentation of data but, as demonstrated earlier, it also provides data analysis and stipulations on the recording of data in its proper place. Three examples:

1. In RDA, Numeric, and/or alphabetic designation and Chronological designation are in the language and script "in which they appear on the sources from which they are taken" (RDA, $\S 1.5$ ). From the table of correspondence provided in Appendix D of RDA, one can see that "2.6.1. Numeric and/or alphabetic" and "2.6.2. Chronological designation" correspond to "Numbering" in area 3 of $\operatorname{ISBD}(\mathrm{CR})$. However, both $\operatorname{ISBD}(\mathrm{G})$ and the consolidated edition of ISBD provide that "terms used in areas 3, 5,7 and $8[\ldots]$ are give in the language and/or script chosen by the national bibliographic agency or other cataloguing agency." This difference is highly relevant in terms of data analysis and contents of data elements.

2 . In the consolidated edition of ISBD, $\S 0.6$, the general rule for abbreviations is "do not abbreviate or abridge in transcribed areas [i.e., 1, 2, 4 and 6] if not on the resource"; in RDA, $\S$ 1.6.7 for "Edition statement, Statement relating to a named revision of an edition, [...] Publisher, distributor, etc., Place of publication, distribution, etc. and Numbering within series" the cataloger is told to "use abbreviations as instructed in Appendix B" (not available yet). A major difference, anyway, remains in the transcription of titles (!) of older monographic resources. ISBD ( $\S 0.6 .6)$ provides that "when contractions and abbreviations in continuance of the manuscript tradition of abbreviating words [...] are found, these may be left as they stand or may be expanded wherever possible"; RDA provides that "If a word appears in an abbreviated form on the source of information, transcribe the abbreviated form as it appears." This difference is highly relevant in terms of data analysis and contents of data elements.

3. Differences are found also in stipulations for devised titles. In RDA, $\S$ 2.3.7.3, the devised title must indicate "either a) the nature of the resource (e.g., map, literary manuscript, diary, advertisement); or b) its subject (e.g., names of persons, corporate bodies, objects, activities, events, geographical area and dates); or c) a combination of the two, as appropriate." Further, devised titles must be enclosed in square brackets only "if the resource is of a type that would normally carry identifying information 
(e.g., a published book" (RDA, § 2.3.7.3.). ${ }^{50}$ In ISBD, "when a resource bears no title, a title is devised and recorded in square brackets. The title thus supplied should be concise, reflecting the area and/or the subject of the resource" (ISBD, § 1.1.4.5.1). In this example, data analysis, sources of information, content, and presentation of devised titles in RDA and ISBD are different. In this simple case, both the schemes have provisions dealing with all these different aspects of a bibliographic language.

These examples show that:

a. ISBD is not only a display format but a complete bibliographic language to describe physical resources;

b. RDA, even if it declares that its main focus is data content, deals also with presentation of data; ${ }^{51}$

c. the use of both the bibliographic languages creates ambiguities and RDA and ISBD are in conflict, as their domains are not clearly delimited.

In 1978, AACR2 was characterized by its descriptive part that represented an innovation in cataloging because of the major importance given to the descriptive portion within the cataloging process. $^{52}$ Chapters 0-12 of Part I drew their structure from stipulations of the ISBDs. As a code, AACR2 broadened and deepened descriptive case studies and for this reason it represented for many catalogs-not just those based on AACR2 - an important point of reference for the descriptive part of the code, especially when ISBD was not sufficiently clear or detailed in its stipulations.

RDA's choice to consider ISBD—on which Part I of AACR2 was founded - as a display format for cataloging data, means radically modifying the foundations of the rules, and making a cataloging revolution as great as in the past, but in this case regression not a progression. RDA also means breaking a long-standing, important, and mutually profitable comparison relationship between the Anglo-American code and ISBD. This regression endangers the standardization that has characterized more than thirty years of cataloging history and greatly contributed to improving both ISBD and AACR.

In fact, there can only be a constructive relationship between the rules and the standard if RDA recognizes that ISBD is a complete bibliographic language for description purposes, different from-and, at the most, completely extraneous to-RDA. As a complete bibliographic language, structured on many levels, ISBD can be adopted or refused, but not reduced to an Appendix or used just for its punctuation. RDA should make a clearer choice with respect to ISBD: either adopting or refusing it completely and in the latter case, proposing an acceptable alternative. In the first case, RDA should recognize and adopt also the other skills of ISBD as a bibliographic language, 
to avoid any conflicting stipulations; in the second case, RDA should supply a complete range of stipulations, including those providing for presentation of data. In both cases, the choice must be clear.

ISBD is an international standard and standards should have a logical level higher than cataloging codes; cataloging codes should deal with those parts of cataloging that are explicitly ignored by international standards.

"RDA identifies the data elements used for descriptive cataloguing and lists them in an order similar to [our emphasis] that found in AACR2. RDA does not provide instructions on the order the elements are to be given in the record (this is governed by encoding standard use); or the order in which they appear in a catalogue display." 53 Nevertheless, if RDA is intended to guide the construction of a catalog, it should specify all the essential characteristics of a catalog, syntax included.

The idea of a catalog, like a text, made up of a sequence of sentences, is neither new nor unfounded and we must preserve such a catalog and its value in terms of overall arrangement of the bibliographic universe and its skill in housing a complex syndetic structure. If we refer to the only three code-makers cited in the ICP draft-Cutter, Ranganathan, and Lubetzky-it is readily evident that they think of the catalog as a text and of its syndetic structure. $^{54}$

Lubetzky notes that "the description and identification of a book on the catalog card should be based on the following principles: A. Arrangement. The items should always be given on the card in their general order of relative importance. This is also the order which normally obtains in the title-page: title, edition statement, and imprint, followed on the card by collation, series note, and supplementary notes." 55 The need of arrangement and order holds true also if today's libraries are increasingly dealing with non-book materials and Web resources. In Lubetzky's view, we should fight—as Panizzi didagainst catalogs as mere finding tools: in fact, we should create Panizzi's "full and accurate catalogue," that is, a catalog capable of identifying and distinguishing the various editions of a work. If we examine the FRBR study, we find that it distinguishes between different editions, using expressions or manifestations. But cataloging rules must provide for a catalog that enables the reader to browse all the descriptions of the different editions and to identify and distinguish among them, and to find one "full and accurate" description of all the attributes together rather than each single attribute of an entity. ${ }^{56}$

A cataloging code should not limit the cataloger to describing data without providing for a form of presentation of those data, nor should it provide multiple but not equivalent choices in the appendices. A catalog is a communication tool, exactly like a language; an accurate index of data does not satisfy our needs of description of the bibliographic universe just as a vocabulary is not sufficient to describe the world. Defining data and their relationships allows one to obtain a dictionary of terms (entities), their values 
(attributes), and their reciprocal interactions (relationships). One should use all of these to describe the bibliographic universe, and should have rules to organize terms, attributes, and relationships in consistent, meaningful, functional, and more complex phrases. That is, a syntax that "specifies the order in which individual vocabulary elements of the language are concatenated to form larger expressions" 57 is needed.

The question is even more complex than this "simple issue" of the bibliographic description: Cutter, Panizzi, Lubetzky, and Ranganathan ${ }^{58}$ provided also for rules for the arrangement of the entries. Is this function irrelevant now? How will present and, above all, future catalogs carry out this basic function?

RDA should incorporate a syntax and that syntax should neither be optional nor an addition to the code, but clearly included within the code itself as mandatory.

\section{RANGANATHAN'S PRINCIPLE OF LOCAL VARIATION}

Identifying relevant entities and their attributes is an essential precondition of the definition of mandatory, conditional, and optional elements of the bibliographic description and the delineation minimal levels of bibliographic description. However, it cannot substitute for the many other functions of a complex language such as ISBD. Further, ISBD is an international standard, and its logical and normative level is higher than that of national and multinational cataloging codes, just as the FRBR model gave guidance for the definition of principles, and as the ICP principles are designed to guide both international standards and national and multinational codes.

The relationships among logical models, principles, standards, and national and multinational codes should be guided by the principle of local variation, already identified by Ranganathan. ${ }^{59}$ Ranganathan dealt widely with the issue of national and multinational codes, due to the particular sociocultural conditions of India. As it is today, at that time India was a mosaic of cultures, religions, and languages, and this required special attention to be paid in rule making. Today, the international cataloging community is confronting a global challenge, in which different cultures, religions, languages, and scripts play a major role in code making.

Ranganathan's principle of local variation recommends that "in any discipline and technique there should be provision for the users of them to secure, for strictly local use, results alternative to those for general use."60 When applied to relationships between different logical levels of cataloging, Ranganathan's law reads:

1. The International Catalogue Code should mark out the factors to be left to the care of each National Catalogue Code; 2. A National Catalogue 
Code should mark out the factors to be left to the care of each Linguistic Catalogue Code in a multilingual country such as India; 3. A National Catalogue code or a Linguistic Catalogue Code, as the case may be, should mark out the factors, to be left to the care of the Local Catalogue Code of each individual library; 4 . The Catalogue Codes in each hierarchical line should be consistent with one another without any mutual contradiction; and 5. Each lower link in each hierarchical line should be a Supplement to all the upper links taken together. ${ }^{61}$

The aim of this principle is to grant familiarity in service to the users; even if a library catalog does have to conform to a pattern conceivable-and prescribed-in the abstract, local variations to favor the library user should also be permitted in a library catalog. Further, "this local colour is to be assumed by the library catalogue in successive stages. Three or four stages are unmistakable-International, National, Linguistic, and Local. Corresponding to each stage there should be a different catalogue code, consistent with the code corresponding to each of the earlier stages." 62

At present we have an international standard bibliographic description and internationally agreed-on Paris Principles. Both constitute an acknowledged heritage for international cataloging practice. Local variations are allowed, of course, but these mean departing from a shared and agreed-on tradition, which has both advantages and risks.

\section{CONCLUSION}

Although our logical model of the bibliographic universe may have changed, neither AACR2 nor the Paris Principles has been abandoned, as the new texts are not yet finished. No one will abandon AACR2 or the Paris Principles before carefully testing the new proposals. This should apply for ISBD too, especially because it still represents the most internationally agreed-on and widespread standard ever, and also because it is the actual basis of FRBR. Above all, it should never be abandoned before answering these questions satisfactorily: What is the substitute for the ISBD? Which tool carries out the functions needed for-and performed up to now by-standard description?

We should also remember our history: in the recent past, the development and the introduction of computers in the world of libraries suggested that main headings — and perhaps headings in general—would not be of any use; we witnessed also "the even more simplistic approach of those who think that the free-text searching used by search engines can substitute for cataloguing." 63 Today we clearly see that the management of any kind of authority records is still an open and difficult question (as FRAD and FRSAR models need to be further developed, evaluated, and adopted). 
To manage the relationships between these many levels, it will be necessary that, at any level (FRBR, ICP, ISBD), stipulations for lower levels be agreed. Further, because in any lower level, it will be necessary that stipulations be provided to respond better to different users' needs, to manage local variations, and to make clear what is covered at which level. Examples already exist; ${ }^{64}$ but these rules must become good practice and should be introduced systematically at the logical level and in international and national cataloging codes.

\section{NOTES}

1. Commissioners Appointed to Inquire into the Constitution and Government of the British Museum, "Report of the Commissioners Appointed to Inquire into the Constitution and Government of the British Museum, with Minutes of Evidence," London, Her Majesty's Stationery Office, 1850, Question no. 9814

2. IFLA Study Group on the Functional Requirements for Bibliographic Records, International Federation of Library Associations and Institutions, "Functional Requirements for Bibliographic Records: Final Report," (München: Saur, 1998). (UBCIM Publications-New Series, v. 19), ISBN 3-598-11382-X.

3. IFLA Meetings of Experts on an International Cataloguing Code, Statement of international cataloguing principles, 2, http://www.ifla.org/VII/s13/icc/imeicc-statement_of_principles-2008.pdf.

4. International Federation of Library Associations and Institutions, International Standard Bibliographic Description (ISBD), preliminary consolidated edition, recommended by the ISBD Review Group; approved by the Standing Committee of the IFLA Cataloguing Section (München: Saur, 2007). http://www.ifla.org/VII/s13/pubs/ISBD-consolidated-July2006.pdf.

5. Joint Steering Committee for Development of RDA, "Outcomes of the Meeting of the Joint Steering Committee Held in Chicago, USA, 13-22 April 2008," http://www.collectionscanada.gc.ca/ jsc/0804out.html.

6. It must be noted that also in AACR2R (1.0D1) a different use of these two elements was provided for in the first level of description.

7. Elaine Svenonius, The Intellectual Foundation of Information Organization (Cambridge, MA: MIT Press, 2000), 62.

8. Ibid., 62.

9. Ibid., 63 .

10. Ibid., 64 .

11. Ibid., 64 .

12. Ibid., 109

13. Seymour Lubetzky, "The Vicissitudes of Ideology and Technology in Anglo-American Cataloging since Panizzi and a Prospective Reformation of the Catalog for the Next Century," in The Future of Cataloging: The Lubetzky Symposium, ed. Tschera Harkness Connell and Robert L. Maxwell (Chicago: American Library Association, 2000), 9.

14. Ibid., 10 .

15. British Museum, Rules for Compiling the Catalogue of Printed Books ... Rev. ed. (London: British Museum, 1936). As Lubetzky wrote, Panizzi "require[s] the reader to look in two places for the information he wants, because [. . . he] want to tell him much more than merely whether or not the library has a particular book [...Panizzi's] rules are concerned not only with the book as a single and separate item, but also as part of a complex of editions and translations of potential interest to an inquiring reader." Lubetzky, "The Vicissitudes of Ideology," 6.

16. International Working Group on FRBR and CIDOC CRM Harmonisation, "FRBR ObjectOriented Definition and Mapping to FRBR-ER (Version 0.9 Draft)," ed. Chryssoula Bekiari, Martin Doerr, and Patrick Le Boeuf, http://cidoc.ics.forth.gr/frbr_drafts.html.

17. This new approach was discussed in: Carlo Bianchini, Pino Buizza, and Mauro Guerrini, "Verso nuovi principi di catalogazione. Riflessioni sull'IME ICC di Francoforte," Bollettino AIB 44, no. 2 (June 2004): 133-152, now in: Mauro Guerrini, with Carlo Bianchini, Pino Buizza, Carlo Ghilli, Antonella 
Novelli, and Lucia Sardo, Verso nuovi principi e nuove regole di catalogazione, ed. Carlo Bianchini, foreword by Alberto Petrucciani; post-foreword by Pino Buizza (Milano: Sylvestre Bonnard, c2005), ISBN 88-86842-76-7.

18. "Functional Requirements for Bibliographic Records," 7.

19. Ibid., 4: "The basic elements of the model developed for the study - the entities, attributes, and relationships-were derived from a logical analysis of the data that are typically reflected in bibliographic records. The principal sources used in the analysis included the International Standard Bibliographic Descriptions (ISBDs), the "Guidelines for Authority and Reference Entries (GARE), the Guidelines for Subject Authority and Reference Entries (GSARE), and the UNIMARC Manual."

20. Functional Requirements for Bibliographic Records, 4.

21. Ibid., 3 .

22. See "Cataloguing Code Comparison for the IFLA Meeting of Experts on an International Cataloguing Code" (July 2003), http://www.d-nb.de/standardisierung/pdf/code_comp_2003_ europe_principles.pdf.

23. International Cataloguing Principles, 1.

24. Ibid.

25. International Conference on Cataloguing Principles, "Statement of Principles," (Paris, 1961), http://www.d-nb.de/standardisierung/pdf/paris_principles_1961.pdf, 1.

26. Charles A. Cutter, Rules for a Dictionary Catalog, 4th ed. (Washington, DC: Government Printing Office, 1904), 11-12.

27. International Cataloguing Principles, 2.

28. Ibid.

29. Svenonius, The Intellectual Foundation of Information Organization, 68.

30. Ibid., p. 71.

31. In Quebec City, during the 74th IFLA General Conference and Council, it was decided to remove "Entities in" based on the worldwide review comments.

32. Svenonius, The Intellectual Foundation of Information Organization, 71.

33. Ibid., 74 .

34. Ibid., 75 .

35. In the survey Cataloguing Code Comparison for the IFLA Meeting of Experts on an International Cataloguing Code, July 2003, prepared during the IME ICC held in Frankfurt, Germany, 16 of 17 national codes answered positively to the question "2.1. Is your cataloguing code based on ISBD for rules for description?" Only the Italian Rules (RICA) declared they did not require ISBD punctuation, but since the 1980s, ISBD has had a very large distribution in Italy. Anyway, the new Italian cataloguing rules, to be published by the end of 2008, are ISBD based. See IFLA Meetings of Experts on an International Cataloguing Code, "Cataloguing Code Comparison for the IFLA Meeting of Experts on an International Cataloguing Code."

36. ISBD, preliminary consolidated edition, ix. Here the ISBD and FRBR relationship is explained, too.

37. Ibid., par. 0.1.1.

38. Tom Delsey, "Mapping ISBD Elements to FRBR Entity Attributes and Relationships" (July 28, 2004), http://www.ifla.org/VII/s13/pubs/ISBD-FRBR-mappingFinal.pdf.

39. "Studies of Descriptive Cataloging: A Report to the Librarian of Congress by the Director of the Processing Department," Washington, DC, United States Government Printing Office, 1946, Appendix A.

40. The name adopted for the RDA is quite explicit about this point.

41. See entry "Description" in Webster's Third New International Dictionary.

42. "Studies of Descriptive Cataloging. Appendix A."

43. "The pragmatics of a language deals with its use or application. An example of a rule governing the application of a bibliographic language is the cataloguing rule that instructs that if an edition statement does not appear on a document being described, the cataloguer is not to make one up." Cf. Svenonius The Intellectual Foundation of Information Organization, 58.

44. Joint Steering Committee for Development of RDA, "RDA: Resource Description and Access. Frequently Asked Questions,” § 4.1, http://www.collectionscanada.gc.ca/jsc/rdafaq.html\#4-1.

45. Ibid., § 4.4, http://www.collectionscanada.gc.ca/jsc/rdafaq.html\#4-4. 
46. FRBR has place holders for subject data and the Group 1, Group 2, and Group 3 entities may all be expressed in authority records, but these are to be developed by FRAD and FRSAR.

47. Examples of rules dealing with the organization of the catalog and presentation of data can be easily found in the codes of Jewett, Panizzi, Cutter, and Ranganathan (and also in RICA-the Italian cataloguing rules published in 1979). Ranganathan writes that "as applied to a library, [...] a catalogue is [...] a methodically arranged record of information about its bibliographical resources" and that "arrangement is the very essence of a catalogue and that our habit is to sort and arrange a set of cards in the first instance by the contents of the topmost line." Shiyali R. Ranganathan, Theory of Library Catalogue (Madras: The Madras Library Association and London: Edward Goldston, 1938), 19 and 31.

48. Precisely, by "Name Heading," then "Name (Main Author, Creator, etc.)," and then "Full Title."

49. Collins Cobuild English Dictionary (London: HarperCollins, 1995).

50. By this choice, RDA tries to accommodate the archival community that wrote to the JSC to ask for this adjustment-otherwise all of their materials would always require square brackets for everything, which they find untenable.

51. In RDA, further simple examples of rules dealing with presentation of data are: use of space, semicolon, space is required in the following RDA rules: 4.15.0.4 and 4.17.0.3; use of space is required in rules: 1.6.5, 4.15.0.3, and 4.15.0.5; use of colon, space is required in rule 4.17.0.3; use of dash is required in rules 4.15.0.3 and 4.18.0.3; use of comma is required in rule 4.18.0.3; use of hyphen is required in rules: $2.6 .1 .3,2.6 .2 .3,2.9 .0 .5,2.10 .6 .7,2.12 .2 .2$, and 4.13.2. This example clarifies the difference between providing for data content and for data presentation. Rule 4.13.2 reads: "If the scale within one map, etc., varies and the outside values are known, record both scales connected by a hyphen"; not to provide for presentation of data, it should rather read: "If the scale within one map, etc., varies and the outside values are known, record both scales." But is it really possible to distinguish content from its form of presentation?

52. There were several earlier codes in the Anglo-American tradition that gave emphasis to description. Panizzi's rules, Jewett's rules, and Cutter's rules gave instruction for description, and the 1949 "Rules for Descriptive Cataloging in the Library of Congress (adopted by the American Library Association)" were also used by major libraries in the Anglo-American tradition until AACR appeared; but the incorporation of an international standard for description first occurred with AACR2.

53. Joint Steering Committee for development of RDA, "RDA: Resource Description and Access. Frequently Asked Questions," § 9.5, http://www.collectionscanada.gc.ca/jsc/rdafaq.html\#9-5.

54. Charles A. Cutter writes: "Let each entry consist of four or five sentences" (Rule 163), and each sentence will be separated by its proper punctuation. But also within the same sentence, an order must be followed (Rules 109 and 136). So that the resulting entries will be uniform; Cutter does emphasize that "uniformity for its own sake is of very little account; for the sake of intelligibility, to prevent perplexity and misunderstanding, it is worth something." This could be not much; but in an international perspective, it has a very important relevance to the last warning, as to style: "it is well to be uniform merely to avoid the question-Why were you not consistent?-." Also Shiyali R. Ranganathan, considering the concept of entry, defines an "ultimate unit-record in a catalogue," and specifies that each entry has its sections - that is, separate paragraphs in an entry-and that "when an entry occurs in a catalogue in book-form, all its sections may occur as separate sentences of a single paragraph." See Shiyali R. Ranganathan, Classified Catalogue Code with Additional Rules for Dictionary Catalogue Code, 5th ed. (Bangalore: Sarada Ranganathan Endowment for Library Science, 1988), p. 169.

55. Seymour Lubetzky, "Manual of Descriptive Cataloging," in Seymour Lubetzky: Writings on the Classical Art of Cataloging, comp. and ed. Elaine Svenonius and Dorothy McGarry (Englewood, CO: Libraries Unlimited, 2001), 42.

56. Mauro Guerrini, "Per una definizione di edizione: le entità Espressione e Manifestazione di FRBR e lo standard ISBD," in L'organizzazione del sapere: studi in onore di Alfredo Serrai, ed. Maria Teresa Biagetti (Milano: Sylvestre Bonnard, 2004), 191-205.

57. Svenonius, The Intellectual Foundation of Information Organization, 58.

58. See Cutter's rule 169 and following ones and Panizzi's rules LXIX-XCI.

59. During the latest revisions of the ICP draft, the introduction of this principle was proposed by a group of Italian experts to give guidelines to solve conflicts within different levels of cataloging rules. In Cutter's words, the principle of local variation is: "No code of cataloguing could be adopted in all points by everyone." Cutter, Rules for a Dictionary Catalog, 9.

60. S. R. Ranganathan, Prolegomena to Library Classification, 3rd ed. (Bombay: Asia Publishing House, 1967), 129. 
61. Ranganathan, Classified Catalogue Code, 65. In Prolegomena to Library Classification (129), Ranganathan applies the law of local variation to a scheme for classification. When a library adopts an alternative scheme for classification, it should stick to it permanently; "but if libraries in accessible neighborhoods have chosen different alternatives, the readers happening to use many of them will be put to an inconvenience, which is worth avoiding. Moreover, a scheme offering virtually different schemes for choice disqualifies itself for use in a national bibliography and in international documentation." Today the concept of neighborhoods is quite different; and what would Ranganathan say about a national code that offers virtually different schemes for choice in the bibliographic description?

62. Ranganathan, Classified Catalogue Code, 65.

63. Michael Gorman, "RDA: Imminent Cataloging Debacle," American Libraries (December 2007), 64, http://al.ala.org/forum/viewtopic.php?t=14.

64. In the preliminary consolidated edition of ISBD, some applications of the principle of local variation were already inserted; for example, the paragraph devoted to principles reads: "Different levels of description will be accommodated, including those needed by national bibliographic agencies, national bibliographies, universities and other research collections"; at $\S 0.1 .3$, provisions for national bibliographic agencies and other cataloguing agencies are different: "National bibliographic agencies are called on to accept responsibility of creating the definitive record for each resource issued in that country. [....] Other cataloguing agencies have a wider choice as they are not providing the definitive record for international exchange. They can select ISBD elements, mandatory, conditional or optional, for inclusion in their own records, provided that the elements selected are given in the prescribed order and transcribed with the prescribed punctuation."; lastly, at $\S 5.1$ Specific material designation and extent reads: "It is anticipated that national bibliographic agencies or other cataloguing agencies will determine the exact terms used as specific material designations that are acceptable to their needs and languages." Even though ISBD seems to ignore school, public, and special libraries, the principle of local variation also provides for them. Also in RDA, $\S 1.6$, dealing with transcriptions, there is a option that suggests a different treatment at a different level of cataloging: "Optionally, if the agency preparing the description has established inhouse guidelines for capitalization, numerals, symbols, etc., or has designated a published style manual, etc., (e.g., the Chicago Manual of Style) as its preferred guide, use those guidelines or that style manual in place of the instructions given under 1.6.1-1.6.8 below and in the Appendices." 